\title{
Focus on the Morphology-Dependent Nanocatalysis Papers in Chinese Journal of Catalysis of the Year 2010
}

\author{
LI Yong* \\ (State Key Laboratory of Catalysis, Dalian Institute of Chemical Physics, Chinese Academy of Sciences, \\ Dalian 116023, Liaoning Province, P. R. China)
}

\begin{abstract}
The size-dependent nanocatalysis has been well studied in the past three decades, while little concern is paid to the shape of the nanoparticles, which can greatly modify the reaction performance by selectively exposing specific crystal facets. This article highlights the recent progress on the morphology-dependent nanocatalysis published in Chinese Journal of Catalysis of the year 2010. This strategy should be workable in designing and preparing efficient nanocatalysts with tunable size and shape.
\end{abstract}

Key Words: Morphology; Nanocatalysis; Nanomaterial

The rapid development in materials science has now made it possible to tailor metal or metal oxide particles with controlled size and shape at nanometer level. As a result, nanocatalysis is experiencing an explosive growth, and the size and shape of a catalyst particle becomes one of the major topics. The size effect of metal nanoparticle has been widely documented and well interpreted in terms of the variation in geometric and electronic properties that largely affect the adsorption and activation of the reactants. In 2010, the Chinese Journal of Catalysis has published more than 30 research articles on this topic. ${ }^{1-31}$ Meanwhile, the performance of the catalyst nanoparticle is also closely associated with its morphology, which is determined by the exposed crystallographic facets. This is termed as morphology-dependent nanocatalysis: catalyst particle with anisotropic shape can greatly modify the reaction performance by selectively exposing specific crystal facets. ${ }^{32}$ Therefore, morphology controllable synthesis of catalyst particles at nanometer level, hopefully less than $10 \mathrm{~nm}$, offers a new approach to mediate the exposure of specific crystallographic planes and the catalytically active sites, and consequently adjust the catalytic properties. The morphology-dependent nanocatalysis has also received increasing attention in recent years and the Chinese Journal of Catalysis has published more than 30 articles on this topic in $2010 .^{33-65}$

Concerning metal nanostructures, Ding et $a .^{34}$ summarized their recent progress on the synthesis of noncrystalline alloy nanotubes. Binary $\mathrm{M}-\mathrm{B}(\mathrm{M}=\mathrm{Fe}, \mathrm{Co}$, and $\mathrm{Ni})$ and ternary NiPB, $\mathrm{NiCuB}$, or $\mathrm{NiCoB}$ nanotubes with the diameter of $20-90 \mathrm{~nm}$ and the length up to several micrometers were prepared by reducing metal ions using $\mathrm{NaBH}_{4}$ in liquid phase with the pres- ence of surfactants. These nanotubes showed much better activities in several hydrogenation reactions than the corresponding nanoparticles. For example, Fe-B nanoparticles gave an $m$-toluidine yield of only $10.7 \%$ in $m$-nitrotoluene hydrogenation, but Fe-B nanotubes offered a yield of $79 \%$, being very close to that obtained on a $\mathrm{Pd} / \mathrm{C}$ catalyst. By reducing the dimension of the Ni-P-B nanotubes, their activity in p-chloro-nitrobenzene hydrogenation was considerably enhanced owing to the enlarging surface area. More importantly, Ni-P-B nanotubes also exhibited a rather stable performance without apparent loss in activity up to 5 cycles. Iron catalysts are typically used in FischerTropsch (FT) synthesis, a crucial reaction in syngas chemistry. Cheng et al. ${ }^{35}$ have fabricated nanochains-like Fe catalysts with the average size of ca $40 \mathrm{~nm}$. These iron catalysts not only exhibited excellent activity for liquid phase FT synthesis at lower reaction temperature, but also offered rather stability for 4 consecutive tests.

Meal oxides are also important catalytic materials, and their performance is strongly dependent on the shape as well. Zhao et $a l .^{36}$ examined the morphology effect of ceria nanoparticles on dehydration of 1,4-butanediol to 3-buten-1-ol. Ceria with regular rectangular morphology was reduced by hydrogen at much lower temperature than the general ceria nanoparticles. The former provided a 3-buten-1-ol yield of about $60 \%$ whereas the later only gave the product yield of $43 \%-47 \%$ under the same reaction conditions. Three-dimensionally ordered macroporous $\mathrm{LaFeO}_{3}$ that was prepared using a colloid crystal template showed a much higher catalytic activity for soot combustion based on the large pores and the uniform channel structure. ${ }^{37}$ Nickel phosphate nanotubes with the outer diameter of

Received: November 3, 2011; Revised: November 9, 2011; Published on Web: November 17, 2011.

${ }^{*}$ Corresponding author. Email: yongli@dicp.ac.cn; Tel: +86-411-84379189; Fax: +86-411-84694447

(C) Editorial office of Acta Physico-Chimica Sinica 
only $7.0 \mathrm{~nm}$ were prepared by a urea-assisted hydrothermal synthesis. ${ }^{38}$ The characteristic feature of this material was that the weak Lewis acid was predominantly present on the surface. In epoxidation of cyclohexene using hydrogen peroxide, the conversion and the selectivity approached $50.6 \%$ and $72.1 \%$, respectively. $\mathrm{SnO}_{2}$, a typical $n$-type semiconductor, is also widely used as oxidation catalysts. ${ }^{39} \mathrm{SnO}_{2}$ nanorods with the diameter of 10-20 nm and the length of several micrometers were synthesized through a solid state reaction. ${ }^{40}$ Hydrogen reduction of this rod-shaped $\mathrm{SnO}_{2}$ occurred at a temperature as low as $453 \mathrm{~K}$, being much lower than the commonly used $\mathrm{SnO}_{2}$ nanoparticles. Moreover, the impact of morphology on the physical and chemical properties has also been theoretically analyzed. A density functional theory study revealed that $\mathrm{Mo}_{12} \mathrm{~S}_{9} \mathrm{I}_{12}$ nanowires not only had a good flexibility but also preserved a special hysteresis during its structural evolution, showing the potential application in catalysis. ${ }^{41}$

These examples have soundly evidenced that the shapes of metal and/or oxide particles do have profound implication in their catalytic properties, although the detailed structure-reactivity relationship still needs further clarification. On the other hand, the concept of morphology-dependent nanocatalysis has also been applied to supported metal catalysts in which the shape of the support altered the metal-support interactions. ${ }^{42-52}$ Sun et al $^{42}$ used carbon materials in the shape of nanofibers, nanotubes, nanocoils, nanohorns, and microbeads to disperse precious metals as catalysts for direct alcohol fuel cells, and found that the improved performance was caused by their special structure, better crystallinity, and faster mass transfer compared with the commercial carbon materials. Carbon nanofibers (CNFs) with fish-bone graphene alignment and carbon nanotubes (CNTs) were also used to support tiny ruthenium nanoparticles. ${ }^{44}$ When used for ammonia decomposition, the $\mathrm{Ru} / \mathrm{CNF}$ catalyst was more active than the $\mathrm{Ru} / \mathrm{CNT}$ sample because the peculiar surface edge structure of the CNF modified the electronic properties of the $\mathrm{Ru}$ nanoparticles. In addition, the shape of the supporting materials also affects the stability of the integrated catalysts. Collagen fiber (CF), originated from animal skin, strongly bonded Pd-Ni nanoparticles with the surface functional groups and thus showed considerably high activity and stability in nitrobenzene hydrogenation. ${ }^{45}$ In addition, palygorskite nanorods, ${ }^{46-48}$ layered double hydroxide $^{49-52}$ and montmorillonite, ${ }^{53}$ and rod-shaped manganese oxide octahedral molecular sieve ${ }^{54}$ have also been reported to be promising supports in prohibiting the sintering of metal particles during the catalytic reactions.

$\mathrm{TiO}_{2}$ is widely used in photocatalysis and solar cells. The photocatalytic performance of $\mathrm{TiO}_{2}$-based nanomaterials is strongly dependent on their crystal phase, particle size, and shape. ${ }^{55}$ Doping of $\mathrm{TiO}_{2}$ with another component has been verified to improve the overall efficiency. The interesting doping materials include carbon nanotubes ${ }^{56}$ hydrotalcite compounds, ${ }^{57}$ iron oxides, ${ }^{58}$ and ZSM-5. ${ }^{59}$ Moreover, the photocatalytic per- formance of $\mathrm{TiO}_{2}$-based materials is also associated with their morphology. $\mathrm{TiO}_{2}$ nanotube arrays with the length of $\sim 300 \mathrm{~nm}$ and films (100 $\mathrm{nm}$ in diameter and $2 \mu \mathrm{m}$ in length) were demonstrated to be highly efficient in photoecatalytic degradation of glucose and methane blue, respectively. ${ }^{60,61} \mathrm{WO}_{3} / \mathrm{TiO}_{2}$ nanorods possessed much higher activity in rhodamine $\mathrm{B}$ decolorization than the typical $\mathrm{P} 25\left(\mathrm{TiO}_{2}\right){ }^{62}$ The photocatalytic activity of $\mathrm{Pt}$ nanoparticles on $\mathrm{TiO}_{2}$ whisker was 1.3 times greater than those supported on $\mathrm{TiO}_{2}$ nanoparticles in phenol degradation. ${ }^{63}$ The morphology-dependent photocatalysis has also been observed over rod-shaped and plate-like $\mathrm{ZnO}$ nanomaterials. ${ }^{64,65}$

It is becoming more apparent that tuning the shape of the catalyst particle at nanometer level can effectively mediate the catalytic efficiency. However, this necessitates developing efficient preparative strategies in controlling the morphology of the catalyst particles so that they can preferentially expose desired crystal facets and in maintaining the structural stability under reaction conditions. Fundamentally, the combination of colloids chemistry, surface science, kinetic studies, and theory analysis will benefit to establish the structure-reactivity relationship of the catalyst particles in terms of size and shape.

\section{References}

(1) Song, H. L.; Yang, J.; Zhao, J.; Chou, L. J. Chin. J. Catal. 2010, $31,21$.

(2) Huang, Z. B.; Yan, X. H.; Jiang, L. C.; Jiang, H. Chin. J. Catal. 2010, 31, 90 .

(3) Liu, B.; Li, W. Z.; Xu, H. Y. Chin. J. Catal. 2010, 31, 1247.

(4) Lin, S. D.; Tang, H. D.; Lü, Z. B.; Liu, C. L.; Cen, Y. Q.; Liu, H. Z. Chin. J. Catal. 2010, 31, 1257.

(5) Liu, Z. Y.; Sun, H. J.; Wang, D. B.; Guo, W.; Zhou, X. L.; Liu, S. C.; Li, Z. J. Chin. J. Catal. 2010, 31, 150.

(6) Wang, J. L.; Liao, C. W.; Chen, Y. D.; Cao, H. Y.; Liu, Z. M.; Gong, M. C.; Chen, Y. Q. Chin. J. Catal. 2010, 31, 404.

(7) Shi, B. B.; Yao, G. X.; Li, G. H.; Zheng, Y. F. Chin. J. Catal. 2010, 31, 466 .

(8) Jiang, X.; Dong, K. Z.; Wang, H. H.; Wang, T. Chin. J. Catal. 2010, 31, 1151.

(9) Gao, D. N.; Wang, S.; Liu, Y.; Zhang, C. X.; Wang, S. D. Chin. J. Catal. 2010, 31, 1363.

(10) Liu, C.; Tan, R.; Yin, D. H.; Yu, N. Y.; Zhou, Y. X. Chin. J. Catal. 2010, 31, 1369.

(11) Huang, W.; Li, W. H.; Sun, J. X.; Yin, L. H. Chin. J. Catal. 2010, 31, 1393.

(12) Wei, Y. C.; Liu, J.; Zhao, Z.; Jiang, G. Y.; Duan, A. J.; He, H.; Wang, X. P. Chin. J. Catal. 2010, 31, 283.

(13) Gu, J. F.; Agula, B.; Jia, M. L.; Liu, Y. P.; Zhaorigetu, B.; Yuan, Z. Y. Chin. J. Catal. 2010, 31, 322.

(14) Chai, X. Y.; Shang, S. Y.; Liu, G. H.; Tao, X. M.; Li, X.; Bai, M. G.; Dai, X. Y.; Yin, Y. X. Chin. J. Catal. 2010, 31, 353.

(15) Huo, C.; Zhang, X. H.; Xia, Q. H.; Yang, X. Z.; Luo, Y.; Liu, H. Z. Chin. J. Catal. 2010, 31, 360. 
(16) Li, J. W.; Ding, Y. J.; Lin, R. H.; Gong, L. F.; Song, X. G.; Chen, W. M.; Wang, T.; Luo, H. Y. Chin. J. Catal. 2010, 31, 365.

(17) Wang, X. Y.; Wang, R.; Ni, J.; Lin, J. X.; Wei, K. M. Chin. J. Catal. 2010, 31, 1452.

(18) Shi, L. H.; Li, X. F.; Li, D. B.; Sun, Y. H. Chin. J. Catal. 2010, $31,1483$.

(19) Shi, R. J.; Wang, F.; Mu, X. L.; Ta, N.; Li, Y.; Huang, X. M.; Shen, W. J. Chin. J. Catal. 2010, 31, 626.

(20) Shi, L. L.; Liu, K. Z.; Zou, X. H.; Jin, M. S.; Suo, Z. H. Chin. J. Catal. 2010, 31, 661.

(21) Wu, D. D.; Guo, J. X.; Li, Y. L.; Gong, M. C.; Chen, Y. Q. Chin. J. Catal. 2010, 31, 567.

(22) Yu, X.; Wang, J. H.; Zhang, L. W.; Hou, Z. Y.; Fei, J. H.; Zheng, X. M. Chin. J. Catal. 2010, 31, 591.

(23) Yuan, P.; Liu, Z, Y.; Zhang, W. Q.; Sun, H. J.; Liu, S. C. Chin. J. Catal. 2010, 31, 769.

(24) Su, J. X.; Zhang, S. P.; Ma, L. Y.; Qu, W.; Zhang, M. B. Chin. J. Catal. 2010, 31, 839.

(25) Wang, H. L.; Yang, Y.; Wang, H.; Qing, M.; Xiang, H. W.; Li, Y. W. Chin. J. Catal. 2010, 31, 809.

(26) Liu, L. C.; Zi, X. H.; Dai, H, X.; Zhao, Z.; Wang, X. P.; He, H. Chin. J. Catal. 2010, 31, 781.

(27) Liu, X. M.; Liang, H. N.; Li, L.; Yang, T. T.; Yan, Z. F. Chin. J. Catal. 2010, 31, 833.

(28) Li, Z.; Fan, H.; Zheng, H. Y.; Liu, Y. Chin. J. Catal. 2010, 31, 471.

(29) He, S. B.; Lai, Y. L.; Bi, W. J.; Yang, X.; Rong, X.; Sun, C. L. Chin. J. Catal. 2010, 31, 435.

(30) Xu, S. L.; Chu, W. L.; Yang, W. S. Chin. J. Catal. 2010, 31, 1342.

(31) Aboul-Gheit, A. K.; Aboul-Enein, A. A.; Awadallah, A. E.; Ghoneim, S. A.; Emam, E. A. Chin. J. Catal. 2010, 31, 1209.

(32) Burda, C.; Chen, X. B.; Narayanan, R.; El-Sayed, M. A. Chem. Rev. 2005, 105, 1025.

(33) Ling, M.; Zhao, G. F.; Cao, F. H.; Lu, Y. Chin. J. Catal. 2010, $31,717$.

(34) Ding, W. P.; Guo, X. F.; Mo, M.; Zhu, Y.; Chen, Y. Chin. J. Catal. 2010, 31, 887.

(35) Cheng, X. F.; Wu, B. S.; Xiang, H. W.; Li, Y. W. Chin. J. Catal. 2010, 31, 579.

(36) He, Y. Y.; Li, Q. B.; Wang, Y. Z.; Zhao, Y. X. Chin. J. Catal. 2010, 31, 619 .

(37) Xu, J. F.; Liu, J.; Zhao, Z.; Zhang, G. Z.; Duan, A. J.; Jiang, G. Y.; Xu, C. M. Chin. J. Catal. 2010, 31, 236.

(38) Wu, G.; Wang, A. J.; Li, X.; Wang, Y.; Hu, Y. K. Chin. J. Catal. 2010, 31, 1139 .

(39) Jiang, H. Y.; Dai, H. X.; Xia, Y. S.; He, H. Chin. J. Catal. 2010, 31, 295.

(40) Zhao, H. Y.; Zhao, Z. Z.; Zhao, Y. F.; Liu, Q. J. Chin. J. Catal.
2010, 31, 44 .

(41) Wen, S. H.; Hou, Z. F.; Liu, J. Y.; He, G. Z. Chin. J. Catal. 2010, 31, 739 .

(42) Tang, S. H.; Sun, G. Q.; Qi, J.; Sun, S. G.; Guo, J. S.; Xin, Q.; Haarberg, G. M. Chin. J. Catal. 2010, 31, 12.

(43) Luo, Y. L.; Liang, Z, X.; Liao, S. J. Chin. J. Catal. 2010, 31, 141.

(44) Duan, X. Z.; Zhou, J. H.; Qian, G.; Li, P.; Zhou, X. G.; Chen, D. Chin. J. Catal. 2010, 31, 979.

(45) Zhuo, L. M.; Wu, H.; Liao, X. P.; Shi, B. Chin. J. Catal. 2010, 31,1465 .

(46) Shi, P. C.; Chen, T. H.; Zhang, X. L.; Chen, D.; Song, L.; Li, J. H. Chin. J. Catal. 2010, 31, 1281.

(47) Li, J. H.; Zhang, X. L.; Chen, T. H.; Liu, H. B.; Shi, P. C. Chin. J. Catal. 2010, 31, 454.

(48) Liu, H. B.; Chen, T. H.; Zhang, X. L.; Li, J. H.; Chang, D. Y.; Song, L. Chin. J. Catal. 2010, 31, 409.

(49) Dhanagopal, M.; Duraiswami, D.; Valentine, R. A.; Ramalinga, V. M.; Thiripuranthagan, S. Chin. J. Catal. 2010, 31, 1200.

(50) Wang, L.; Meng, X. J.; Xiao, F. S. Chin. J. Catal. 2010, 31, 943.

(51) Chen, J.; Zhang, Q. H.; Fang, W. H.; Wang, Y.; Wan, H. L. Chin. J. Catal. 2010, 31, 1061.

(52) Liu, S. Y.; Zhou, Q. Z.; Jin, Z. N.; Jiang, H. J.; Jiang, X. Z. Chin. J. Catal. 2010, 31, 557.

(53) Zhou, L. M.; Fu, H. Y.; Li, Q.; Chen, H.; Li, R. X.; Li, X. J. Chin. J. Catal. 2010, 31, 695.

(54) Liu, X. S.; Lu, J. Q.; Wang, X. X.; Luo, M. F. Chin. J. Catal. 2010, 31, 181.

(55) Chen, S. S.; Zhu, Y. H.; Li, W.; Liu, W. J.; Li, L. C.; Yang, Z. H.; Liu, C.; Yao, W. J.; Lu, X. H.; Feng, X. Chin. J. Catal. 2010, 31, 605.

(56) Zhang, K.; Meng, Z. D.; Oh, W. C. Chin. J. Catal. 2010, 31, 751.

(57) Chen, W.; Li, D. Z.; He, S. H.; Shao, Y.; Huang, Y.; Fu, X. Z. Chin. J. Catal. 2010, 31, 1037.

(58) Kuang, J. D.; Lin, B. Z.; Chen, Y. L.; Pian, X. T.; Zhang, K. Z.; Zhang, O. Chin. J. Catal. 2010, 31, 1399.

(59) Guo, P.; Liu, C. Y.; Gao, M.; Wang, X. S.; Guo, H. C. Chin. J. Catal. 2010, 31, 573.

(60) Liu, B. C.; Li, J. H.; Zhou, B. X.; Zheng, Q.; Bai, J.; Zhang, J. L.; Liu, Y. B.; Cai, W. M. Chin. J. Catal. 2010, 31, 163.

(61) Zhang, X.; Ling, Y. H.; Liao, L.; Niu, Z. Y.; Chen, S. L.; Zhao, C. G. Chin. J. Catal. 2010, 31, 1300.

(62) Liu, Y.; Wang, S.; Wang, T.; Xu, Z. L.; Chen, W. X.; Jinag, J.; Wei, J. H. Chin. J. Catal. 2010, 31, 485.

(63) Ding, Y. L.; Bai, Y.; Li, W.; Chen, S. S.; Zhu, Y. D.; Zhu, Y. H.; Yang, Z. H.; Lu, X. H. Chin. J. Catal. 2010, 31, 1271.

(64) Zhu, S. M.; Li, Y. S.; Zhang, Z. H. Chin. J. Catal. 2010, 31, 380.

(65) Fu, T. H.; Gao, Q. Q.; Liu, F.; Dai, H. J.; Kou, X. M. Chin. J. Catal. 2010, 31, 797. 